\title{
Pediatrik Gastrointestinal Endoskopi Uygulamasında Anestezi Deneyimlerimiz: Retrospektif Çalışma
}

\author{
Our Anesthesia Experience in Pediatric Gastrointestinal Endoscopy \\ Application: Retrosepective Study

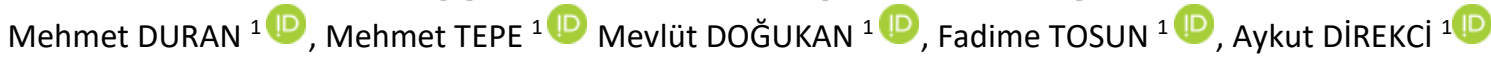 \\ ${ }^{1}$ Adıyaman Üniversitesi Tıp Fakültesi Anesteziyoloji ve Reanimasyon Anabilim Dalı, Adıyaman, Türkiye.
}

Öz.

Amaç: Son yıllarda artan pediatrik gastrointestinal endoskopi uygulamasında hasta konforu ve işlemin daha kolay uygulanabilmesi açısından derin sedasyona ihtiyaç duyulmaktadır. Bu çalışmadaki amacımız ketamin ve propofol kombinasyonun pediatrik gastrointestinal endoskopide etkinliğini araştırmaktır. Materyal ve metod: Aralık 2017 ve Mart 2019 tarihleri arasında pediatrik gastrointestinal endoskopi sırasında ketamin ve propofol kombinasyonu ile sedoanaljezi yapılan hastalar retrospektif olarak incelendi. Hastaların yaşı, cinsiyeti, endikasyonları, ek ilaç ihtiyacı, komorbit durumlar, işlemin endikasyonları, meydana gelen komplikasyonlar, işlem süresi, derlenme süresi ve işlem sonrası bekleme süresi kaydedildi.

Bulgular: Çalışmaya 202 erkek, 195 kadın toplam 397 hasta dahil edildi. Ortalama yaşları $9.22 \pm 4.72$ idi. Vakaların endoskopik ön tanıları incelendiğinde, en yüksek oranda (\%53.4) karın ağrısı, ikinci olarak çölyak hastalığı ön tanısı (\%15.3) ile alındığı dosya taramasından anlaşıldı. Vakaların işlem süresi $19.77 \pm 8.48$, derlenme süresi $10.3 \pm 3.83$ ve işlem sonrası bekleme süresi $17.41 \pm 4.19$ olarak tespit edildi. Hastaların \%20.7'sinda ek propofol ihtiyacı olmuştur. Vakaların, \%3.3'nde (13 vaka) komplikasyon görülmüştür

Sonuç: Yaptığımız retrospektif incelemede, 397 hastada propofol ve ketamin kombinasyonu ile başarılı bir şekilde sedasyon sağlanmış olup düşük komplikasyon oranları tespit edilmiştir. Bu nedenle pediatrik gastrointestinal endoskopi uygulamalarında propofol ve ketamin kombinasyonun güvenle uygulanabileceğini düşünmekteyiz

Anahtar Kelimeler: Pediyatrik gastrointestinal endoskopi, Sedasyon, Propofol, Ketamin

\section{Abstract}

Background: In the practice of pediatric gastrointestinal endoscopy, which has increased in recent years, deep sedation is needed for patient comfort and easier application of the procedure. Our aim in this study is to investigate the efficacy of ketamine and propofol combination in pediatric gastrointestinal endoscopy.

Materials and Methods: Patients who was applied sedoanalgesia with a combination of ketamine and propofol for pediatric gastrointestinal endoscopy between December 2017 and March 2019, were screened. The patients' age, gender, need for additional medication, comorbid conditions, indications of the procedure, complications, duration of the procedure, recovery time and waiting period after the procedure were recorded.

Results: A total of 397 patients, 202 male and 195 female, were included in the study. Their mean age was $9.22 \pm 4.72$ years. When the endoscopic prediagnoses of the cases were examined, the highest rate (53.4\%) was abdominal pain and the second prediagnosis of celiac disease $(15.3 \%)$ was found. The duration of the procedure was $19.77 \pm 8.48$, the recovery period was $10.3 \pm 3.83$ and the waiting time after the procedure was $17.41 \pm 4.19$. Additional propofol was needed in $20.7 \%$ of the patients. Complications were seen in $3.3 \%$ ( 13 cases) of cases.

Conclusion: In our retrospective review, sedation was successfully achieved with the combination of propofol and ketamine in 397 patients, and low complication rates were detected. Therefore, we think that the combination of propofol and ketamine can be safely applied in pediatric gastrointestinal endoscopy applications.

Keywords: Pediatric gastrointestinal endoscopy, Sedation, Propofol, Ketamine
Sorumlu Yazar / Corresponding Author

Dr. Mehmet DURAN

Adıyaman Üniversitesi Tıp Fakültesi Anesteziyoloji ve Reanimasyon Anabilim Dalı, Adıyaman, Türkiye.

e-mail: md021979@hotmail.com

Geliş tarihi / Received:

22.09.2021

Kabul tarihi / Accepted:

10.11.2021

DOI: $10.35440 /$ hutfd.998930 


\section{Giriş}

Çocukluk çağında gerçekleştirilen gastrointestinal endoskopi (GE) işlemi son yıllarda önemli ölçüde artmış ve pediatrik gastrointestinal hastalıkların tanısı ve tedavisinde, yaygın hale gelmiştir (1). GE çeşitli endikasyonlarla yapılmaktadır. Daha önceleri sıklıkla özofagusta daralma, yabancı cismin bulunması ve çıkarılması, özofagus varisi tanı ve tedavisi, perkütan endoskopik gastrostomi (PEG) açılması ve kalın barsak poliplerinin çıkarılması iken günümüzde en sık karın ağrısı, gastrit ve çölyak gibi hastalıklarda uygulanmaktadır $(2,3)$.

Küçük çocuklar, genellikle anlamadıkları prosedürler sırasında işbirliği yapmayabilirler. Ayrıca, amaçlanan sedasyon yeterli değilse, ebeveynlerinden ayrılmanın neden olduğu psikolojik travma ve prosedür sırasında ağrı yaşama olasılıkları daha yüksektir. Pediatrik endoskopi, manyetik rezonans görüntüleme veya elektroensefalografiden farklı olarak, genellikle analjezik ilaçların kullanılmasını gerektiren ağrılı bir prosedürdür. Pediatrik hastalarda işlem konforu ve hastanın ajitasyonu açısından derin sedasyona ihtiyaç duyulmaktadır. Özellikle hasta işlemde uyum göstermezse, komplikasyon riski artar (4-6). Avrupa Pediatrik Gastroenteroloji Hepatoloji ve Beslenme Derneği (ESPGHAN) pediatrik GE için genel anestezi (GA) veya GA yoksa derin sedasyon önermektedir (6). Intravenöz (iV) sedasyonun etkisinin hızlı başlangıçlı, titre edilebilir olması ve GA'ye göre daha kısa uyanma süresi avantajlarına sahiptir. Ayrıca, daha az bulantı ve kusma, sekresyon kontrolü ve öğürme refleksinin azalması gibi avantajları da vardır (7).

Pediyatrik sedasyon için kullanılan ilaç kombinasyonları ketamin, propofol, midazolam, fentanil ve petidindir (8). Propofol en sık kullanılan ajan olmakla birlikte temel avantajları, hızlı anestezi indüksiyonu ve düşük dozlarda kardiyovasküler parametrelerin iyi korunmasıdır. Böylece sedasyon sorunsuzca sürdürülebilmektedir (9).

Bu çalışmadaki amacımız; pediyatrik gastrointestinal endoskopi girişimi nedeniyle ketamin ve propofol uygulanan hastalarda, bu kombinasyonun etkinliğini literatür eşliğinde tartışmaktır.

\section{Materyal ve Metod}

Çalışmamız Yerel Etik Kuruldan (Adıyaman Üniversitesi Girişimsel Olmayan Klinik Araştırmalar Etik Kurulu Tarih 16/04/2019 Karar sayısı:2019/3-25) onay alındıktan sonra 1 Aralık 2017 ve 1 Mart 2019 tarihleri arasında, Pediyatrik Gastroenteroloji Kliniği tarafından gastrointestinal endoskopide anestezi uygulanan hastalar retrospektif olarak incelendi. Ameliyathane ve yoğun bakım ünitesinde yapılan endoskopik incelemeler, propofol ve ketamin dışında başka sedatif ilaç kullanılan hastalar çalışma dışı bırakıldı. Tüm hastalar işlem öncesi preoperatif anestezi polikliniğinde değerlendirilmiştir.

İşlem esnasında demografik veriler, ASA, GE endikasyonları, uygulamada kullanılan ilaçlar, meydana gelen komplikasyonlar, işlem süresi, derlenme süresi ve işlem sonrası bekleme süresi kaydedildi. İşlem süresi, endoskobun ağız boşluğundan veya anüsten geçmesinden çıkarılmasına kadar geçen süre olarak kaydedildi. Derlenme süresi, bilişsel parametreler olarak göz açma, sözlü yanıt ve yönelim düzelmesi kontrol edilerek belirlenmektedir. Hastalara işlem öncesi iv yola kanül konularak 4 $\mathrm{cc} / \mathrm{kg} / \mathrm{saat}$ hızla uygun mayi gönderildi.

Midazolam iV yol ile $0.03 \mathrm{mg} / \mathrm{kg}$ verildikten sonra, hastalar işlem masasına alındılar. Non-invaziv kan basıncı, pulse oksimetre, EKG monitorizasyonu yapıldı. 2 lt/dk nazal oksijen verildi. Hastaya pozisyon verildi. Sonra sedasyon için hastalara $1 \mathrm{mg} / \mathrm{kg}$ propofol ve $0.5 \mathrm{mg} / \mathrm{kg}$ ketamin iV yol ile verildikten sonra işleme başlandı. İşleme tepki veren hastalara $0.5 \mathrm{mg} / \mathrm{kg}$ propofol ilave doz olarak eklendi. İşlem sırasında periferik oksijen saturasyonun \%92 ve daha aşağı değerlere düşüşü hipoksi olarak değerlendirildi. Kalp tepe atımının yaşa göre belirlenmiş fizyolojik değerlerinin altına düşmesi bradikardi olarak belirlendi.

İstatistiksel analiz: Katılımcıların demografik değişkenler açısından sıklıkları, oranları, ortalama ve standart sapma değerleri betimsel istatistikler olarak sunulmuştur. Tablolarda sürekli değişkenler için; en düşük ve en yüksek değerler, ortalama ve standart sapma değerleri, kategorik değişkenler için ise, sayı ve yüzde değerleri rapor edilmiştir. Bu çalışmada verilerin analizleri SPSS 25 (IBM Corp. Released 2017. IBM SPSS Statistics for Windows, Version 25.0. Armonk, NY: IBM Corp.) programı aracılığı ile gerçekleştirilmiştir.

\section{Bulgular}

Bu çalışmanın örneklemi yaşları 1 ile 17 arasında değişen (Ort.= 9.22 \pm 4.72$)$ 202'si (\%50.9) erkek, 195'i (\%49.1) kadın olmak üzere 397 vakadan oluşturuldu. Vakaların cinsiyetlere göre dağılım oranları, ASA değerleri, ek doz ilaç ihtiyacı, komplikasyonlar Tablo 1'de sunulmuştur.

Tablo 1. Cinsiyet, ASA* Sınıflandırması, komplikasyonlar, ek doz ilaç ihtiyacının gösterimi

\begin{tabular}{llll}
\hline Değişkenler & & $\mathbf{n}$ & \% \\
\hline \multirow{2}{*}{ Cinsiyet } & Erkek & 202 & 50.9 \\
& Kadın & 195 & 49.1 \\
\hline \multirow{2}{*}{ ASA* Sınıflandırması } & 1 & 337 & 84.8 \\
& 2 & 60 & 15.2 \\
\hline \multirow{2}{*}{ Komplikasyon } & Var & 13 & 3.3 \\
& Yok & 384 & 96.7 \\
\hline \multirow{2}{*}{ Ek doz } & Var & 82 & 20.7 \\
& Yok & 315 & 79.3 \\
\hline
\end{tabular}

*Amerikan Anestezi Derneği

Vakaların, \% 3.3'ünde (13 vaka) komplikasyon görülmüştür. 9 hastada hipoksi, 4 hastada bradikardi görüldü. Hipoksi görülen hastalar, maske ile oksijen verilerek normale döndürüldü. Bradikardi gelişen 1 hastaya ise 0.01 $\mathrm{mg} / \mathrm{kg}$ atropin verilerek tedavi edildi. Vakaların \%75.06'üne endoskopi, \% 13'una kolonoskopi, \% 10'unda ise endoskopi-kolonoskopi, PEG açılması işlemi yapıldı. 
Yapılan işlemler ve işlemlerin oranları Tablo 2'de sunulmuştur. Vakaların endoskopi endikasyonları incelendiğinde, en yüksek oranda (\%53.4) karın ağrısı olduğu, sonrasında çölyak hastalığı şüphesinin (\%15.3) olduğu görülmüştür (Tablo 3). Vakaların yaş, ağırlık, işlem süresi, derlenme süresi ve işlem sonrası bekleme süresine ilişkin en düşük ve en yüksek değerler, ortalamaları ve standart sapmaları incelenmiştir (Tablo 4).

Tablo 2. Vakalara yapılan işlemlerin oranları

\begin{tabular}{lll} 
İşlemler & $\mathbf{n}$ & $\%$ \\
\hline Endoskopi & 298 & 75.1 \\
Kolonoskopi & 52 & 13.1 \\
Endoskopi + Kolonoskopi & 40 & 10 \\
PEG* & 7 & 1.7 \\
Toplam & 397 & 100 \\
\hline
\end{tabular}

*PEG: perkütan endoskopik gastrostomi

Tablo 3. Vakaların endoskopi endikasyon oranları

\begin{tabular}{lll}
\hline Tanılar & $\mathbf{n}$ & \% \\
\hline Karın ağrısı & 212 & 53.4 \\
Çölyak şüphesi & 61 & 15.3 \\
İshal & 29 & 7.3 \\
Gís* kanaması & 32 & 8 \\
İrritabl Barsak Hastalığı & 27 & 6.8 \\
Yabancı cisim & 16 & 4 \\
Diğer & 18 & 4.5 \\
Toplam & 397 & 100 \\
\hline
\end{tabular}

*Gastrointestinal sistem

Tablo 4. Vakaların yaş, ağırlık, işlem süresi, derlenme süresi ve işlem sonrası bekleme süresine ilişkin betimsel istatistikler

\begin{tabular}{lcccc}
\hline Değişkenler & $\mathbf{n}$ & En Düşük & En Yüksek & Ort.- Std. Sp \\
\hline Yaş (yıl) & 397 & 1 & 17 & $9.22 \pm 4.72$ \\
Ağırlık (kg) & 397 & 7 & 78 & $31.99 \pm 18.50$ \\
İşlem Süresi (dakika) & 397 & 5 & 42 & $19.77 \pm 8.48$ \\
$\begin{array}{l}\text { Derlenme Süresi } \\
\text { (dakika) }\end{array}$ & 397 & 3 & 20 & $10.3 \pm 3.83$ \\
İşlem sonrası & & & & \\
bekleme Süresi (dakika) 397 & 10 & 25 & $17.41 \pm 4.19$ \\
\hline
\end{tabular}

\section{Tartışma}

Gastrointestinal sistemin endoskopisi, özofagustan terminal ileuma kadar mukozalarının incelenmesine imkan sağlayarak, bu bölgelerdeki hastalıkların tanısında ve tedavisinde yaygın olarak kullanılmaktadır(10).

Gastrointestinal sistem endoskopisi ameliyathanede GA verilerek yapılabileceği gibi; ameliyathane dışında anestezik ilaçlarla sedasyon sağlanarak endoskopi ünitesinde de yapılmaktadır (11). Gastrointestinal sistem endoskopisinde iV sedasyon çok sık kullanılmaktadır. Bunun en önemli nedeni hızlı sirkülasyon, düşük maliyetle uygulanabilir olması, daha az personel ile uygulanabilmesidir (12). Endoskopi gibi pediatrik GE prosedürlerinin başarılı bir şekilde uygulanması için hem psikolojik olarak rahat olması, hemde bedensel olarak önemli ölçüde hareketsiz- leştirilmesi şarttır (13). Ancak çocuklarda endoskopi işlemi için hangi ilaçlarla endoskopi sağlanacağı konusunda ortak bir görüş bulunmamaktadır. $(14,15)$

Benzodiazepinler, anksiyolitik ve amnezik etkileri nedeniyle diğer anesteziklerle kombine edilerek sıkça kullanımaktadır (12).

Propofolde giderek artan sıklıkta endoskopi girişimlerinde sedasyon amaçlı tercih edilmektedir (15). Propofolün etkisinin geri dönmesi oldukça hızlıdır, işlem sonrası dönemde erken taburculuğu kolaylaştırır. Ajitasyon, bulantı veya kusma gibi komplikasyonlar daha az görülür (9). Propofolün bu olumlu etkisi, onu GE için popüler bir anestezik ajan haline getirmiştir. Bununla birlikte, endoskopi yapılan çocuklarda propofol ile ilgili güvenlik verileri eksiktir ve solunum depresyonu ve kardiyovasküler dengesizliği indükleme potansiyeli nedeniyle endişeleri artmıştır (12). Kaddu ve ark.(17) tarafından yapılan bir çalışmada üst gastrointestinal sistem endoskopisi için propofol verilen pediyatrik hastaların \%20'sinin geçici apne yaşadığını bildirmişlerdir. Ketamin, analjezik özelliklere sahiptir ve sempatik stimülasyon yoluyla kan basıncı stabilitesini destekler, propofol-ketamin kombinasyonu daha stabil hemodinami ve derin sedasyon sağlar $(18,19)$.

Tosun ve ark. (19) propofol + ketamin kombinasyonunu, propofol + fentanil kombinasyonu ile karşılaştırdıkları çaIışmada her iki kombinasyonda eşit derecede etkili sedasyon ve benzer düşük düzeyde hafif solunum sıkıntıları olduğunu tespit etmişlerdir. Ketamin kullanımının, daha iyi bir endoskop yerleştirme toleransı, ancak daha fazla öksürük, kusma, baş dönmesi ve diplopi insidansı ile ilişkili olduğu sonucuna varılmıştır. Yaptığımız çalışmada propofol ile birlikte, düşük doz ketamin kullanmamız yeterli seviyede derinlik sağlamış ve hastaların \%79'u ilave propofole ihtiyaç duymamıştır. Bu durumun ketaminin düşük doz kullanımına ve propofolun olumlu etkilerine bağlı olduğunu düşünmekteyiz.

Ament ve ark.(20) tarafından 5840 pediyatrik olguda yapılan endoskopik işleminde \%3.7 oranında komplikasyon bildirmişlerdir. Martinez ve ark. (15) tarafından 154 çocuk vakada yapılmış çalışmada, vakaların \%9'unda hipoksi bildirilmiştir. Bu vakaların tamamı oksijen desteği ile normale dönmüştür. Ketamin ve midazolam ile meperidin ve midazolamın karşılaştırıldığı başka bir çalışmada ise ketamin ve midazolam kullanılan vakalarda daha düşük oranda hipoksi görüldüğü bildirilmiştir (21). Soyalp ve ark. Tarafından yapılan çalışmada daha çok propofol-midazolam kombinasyonu kullanılmış olup, \%5.5 komplikasyon oranı bildirilmiştir (22). Yaptığımız çalışmada hastaların \%3.3'ünde komplikasyon görülmüş ve bu hastaların 9 tanesinde oksijen desteği verilerek normal oksijen seviyelerine geldiği tespit edilmiştir. Dört hastada ise bradikardi gelişmiş ve $0.01 \mathrm{mg} / \mathrm{kg}$ dozda atropin verilerek tedavi edilmiştir.

Koh ve ark.(23) Çocuk hastanesi endoskopi ünitesinde 4 yıl süreyle endoskopi yapılan hastaları retrospektif olarak incelenmiş; işlemlerin \%68'i tek başına özofago-gastro- 
duodenoskopi, \%30'ü kolonoskopi veya kolonoskopi ve özofago-gastro-duodenoskopi, \%2'si ise diğer prosedür kombinasyonları şeklinde belirtilmişlerdir. Yine endoskopi endikasyonları incelendiğinde \%40 abdominal ağrı, \%12 reflü ve kusma, \%14 Gis kanaması, \%34 diğer (ishal, ülseratif kolit vs.) olarak tespit edilmiştir. Yaptığımız çalışmada ise vakaların \%75.1'i endoskopi, \%13.1'i kolonoskopi, $\% 10$ 'da ise endoskopi ve kolonoskopidir. Endoskopi endikasyonları ise; \%53.4 oranında karın ağrısı ve \%15.3 Çölyak şüphesi, \%7.3 oranında ise ishal olduğu görülmüştür. Kohl ve ark. (23) yine aynı çalışmada ortalama anestezi süresini EGD (özefago-gastro-duodenoskopi) için 38 dakika, kolonoskopi için 55, EGD + kolonoskopi için 66 dakika ve EGD ile diğer prosedürler için 48 dakika olarak bildirmiştir. Ortalama derlenme süresi 36 dakika (10-130 dakika) olarak belirtilmiştir. Yang ve ark. (24) yaptığı çalışmada derlenme süresini üst GE $23.8 \mathrm{dk}$. kolonoskopide $28 \mathrm{dk}$. olarak bulmuşlardır. Schmitz ve ark. (25) tarafından yürütülen MRI sonrası derlenme süresine ilişkin bir çalışmanın sonuçları, düşük doz propofol ile ketamin kullanan hastalarda yüksek dozda propofol ile sedasyon sağlanan gruptan daha kısa süreliydi. Yaptığımız çalışmada ise derlenme süresi 10.3 dakika (3-20dakika) olarak tespit edilmiş olup, diğer çalışmalardan daha kısadır. Derlenme süremizin kısa olmasını düşük doz propofol ve ketamin kombinasyonuna bağlıyoruz.

Motamed ve ark.(26) 150 çocuk hastada yapılan çalışmasında olguları üç gruba ayırmışlardır. 1. Gruba plasebo-midazolam, 2. Gruba midazolam-ketamin ve 3. Gruba da midazolam-fentanil verilerek sedasyon sağlanmıştır. Sedasyonun yetersizliğine bağlı başarısız işlem oranları gruplar arasında sırasıyla \%10.2, \%8.0 ve \%3.9 olarak bildirilmiştir. Bizim yaptığımız çalışmada yetersiz sedasyona bağı başarısız işlem görülmemiştir.

\section{Çalışmanın sınırlılıkları}

Bu çalışmanın bazı sınırlılıkları vardı; ilki verilerin retrospektif olarak elde edilmiş olması, İkincisi hastanemizde pediyatrik endoskopi ünitesi açıldıktan hemen sonraki ilk vakalar incelenmiştir. Eksikler ve bazı deneyimler bu hastalarla beraber elde edilmiştir. İleriki çalışmalarda sedasyon için farklı ilaç kombinasyonlar ile karşılaştırabilir.

\section{Sonuç}

Çocuklarda propofol ve ketamin kombinasyonu ile sedasyon pediatrik GE de güvenle uygulanabilir.

Etik onam: Çalışma için Adıyaman Üniversitesi Girişimsel Olmayan Klinik Araştırmalar Etik Kurulundan etik onayı alındı (Tarih 16/04/2019; Karar sayısı:2019/3-25).

\section{Yazar Katkıları:}

Konsept: M.D.,M.D.,M.T.,F.T.,A.D.

Literatür Tarama: M.T.,F.T.,A.D.,M.T.

Tasarım: M.D.,M.D.,F.T.

Veri toplama: M.D.,M.D.,M.T.,A.D.

Analiz ve yorum: M.D.,M.D.,M.T

Makale yazımı: M.D. ,M.T.,A.D

Eleştirel incelenmesi: F.T.,A.D.
Çıkar Çatışması: Herhangi bir çıkar çatışmamız bulunmamaktadir.

Finansal Destek: Araştırma kapsamında herhangi bir kurum ya da kuruluştan finansal destek sağlanmamıştır.

\section{Kaynaklar}

1. Friedt $\mathrm{M}$, Welsch S. An update on pediatric endoscopy. Eur J Med Res. 2013 Jul 25;18(1):24. doi: 10.1186/2047-783X-18-24. PMID: $23885793 ;$ PMCID: PMC3751043.

2. Franciosi JP, Fiorino K, Ruchelli E, Shults J, Spergel J, et al. Changing indications for upper endoscopy in children during a 20-year period. J Pediatr Gastroenterol Nutr. 2010 Oct;51(4):443-7. doi: 10.1097/MPG.0b013e3181d67bee. PMID: 20562722; PMCID: PMC2946469.

3. Isik IA, Iyilikçi L, Ozturk Y, Adiyaman E. Sedation Practice Outside the Operating Room for Pediatric Gastrointestinal Endoscopy. Indian Pediatr. 2015 Nov;52(11):989-90. doi: 10.1007/s13312-015-0761-4. PMID: 26615354.

4. American Academy of Pediatrics; American Academy of Pediatric Dentistry, Coté CJ, Wilson S; Work Group on Sedation. Guidelines for monitoring and management of pediatric patients during and after sedation for diagnostic and therapeutic procedures: an update. Pediatrics. 2006 Dec;118(6):2587-602. doi: 10.1542/peds.2006-2780. PMID: 17142550.

5. Lightdale JR, Liu QY, Sahn B, Troendle DM, Thomson M, Fishman DS; NASPGHAN Endoscopy and Procedures Committee. Pediatric Endoscopy and High-risk Patients: A Clinical Report From the NASPGHAN Endoscopy Committee. J Pediatr Gastroenterol Nutr. 2019 Apr;68(4):595-606.

6. Tringali A, Thomson M, Dumonceau JM, Tavares M, Tabbers MM, Furlano R, et al. Pediatric gastrointestinal endoscopy: European Society of Gastrointestinal Endoscopy (ESGE) and European Society for Paediatric Gastroenterology Hepatology and Nutrition (ESPGHAN) Guideline Executive summary. Endoscopy. 2017 Jan;49(1):83-91. doi: 10.1055/s-0042-111002. Epub 2016 Sep 12. PMID: 27617420.

7. Krauss B, Green SM. Procedural sedation and analgesia in children. Lancet. 2006 Mar 4;367(9512):766-80. doi: 10.1016/S0140-6736(06)68230-5. PMID: 16517277.

8. Scottish Intercollegiate Guidelines Network. SIGN Guideline 58: safe sedation of children undergoing diagnostic and therapeutic procedures. Paediatr Anaesth. 2008 Jan;18(1):11-2. doi: 10.1111/j.1460-9592.2007.02405.x. PMID: 18095959.

9. Apfelbaum JL, Grasela TH, Hug CC Jr, McLeskey CH, Nahrwold $\mathrm{ML}$, Roizen MF, et al. The initial clinical experience of 1819 physicians in maintaining anesthesia with propofol: characteristics associated with prolonged time to awakening. Anesth Analg. 1993 Oct;77(4 Suppl):S10-4. PMID: 8214691.

10. Nguyen VX, Le Nguyen VT, Nguyen CC. Appropriate use of endoscopy in the diagnosis and treatment of gastrointestinal diseases: up-to-date indications for primary care providers. Int J Gen Med. 2010 Nov 1;3:345-57. doi: 10.2147/IJGM.S14555. PMID: 21116340; PMCID: PMC2990396.

11. Lightdale JR, Mahoney LB, Schwarz SM, Liacouras CA. Methods of sedation in pediatric endoscopy: a survey of NASPGHAN members. J Pediatr Gastroenterol Nutr. 2007 Oct;45(4):500-2. doi: 10.1097/MPG.0b013e3180691168. PMID: 18030225.

12. Fredette ME, Lightdale JR. Endoscopic sedation in pediatric practice. Gastrointest Endosc Clin N Am. 2008 Oct;18(4):739-51, ix. doi: 10.1016/j.giec.2008.06.006. PMID: 18922412.

13. Khalila A, Shavit I, Shaoul R. Propofol Sedation by Pediatric Gastroenterologists for Endoscopic Procedures: A Retrospective 
Analysis. Front Pediatr. 2019 Mar 26;7:98. doi: 10.3389/fped.2019.00098. PMID: 30972312; PMCID: PMC6445344.

14. Amornyotin $S$, Aanpreung P, Prakarnrattana U, Chalayonnavin W, Chatchawankitkul S, Srikureja W. Experience of intravenous sedation for pediatric gastrointestinal endoscopy in a large tertiary referral center in a developing country. Paediatr Anaesth. 2009 Aug;19(8):784-91. doi: 10.1111/j.14609592.2009.03063.x. PMID: 19624366.

15. Martinez JL, Sutters KA, Waite S, Davis J, Medina E, Montano $\mathrm{N}$, et al. A comparison of oral diazepam versus midazolam, administered with intravenous meperidine, as premedication to sedation for pediatric endoscopy. J Pediatr Gastroenterol Nutr. 2002 Jul;35(1):51-8. doi: 10.1097/00005176-200207000-00012. PMID: 12142810 .

16. Cohen LB, Wecsler JS, Gaetano JN, Benson AA, Miller KM, Durkalski V, et al. Endoscopic sedation in the United States: results from a nationwide survey. Am J Gastroenterol. 2006 May;101(5):967-74. doi: 10.1111/j.1572-0241.2006.00500.x. PMID: 16573781.

17. Kaddu R, Bhattacharya D, Metriyakool K, Thomas R, Tolia V. Propofol compared with general anesthesia for pediatric Gl endoscopy: is propofol better? Gastrointest Endosc. 2002 Jan;55(1):27-32. doi: 10.1067/mge.2002.120386. PMID: 11756910.

18. Green SM, Klooster M, Harris T, Lynch EL, Rothrock SG. Ketamine sedation for pediatric gastroenterology procedures. J Pediatr Gastroenterol Nutr. 2001 Jan;32(1):26-33. doi: 10.1097/00005176-200101000-00010. Erratum in: J Pediatr Gastroenterol Nutr 2001 Feb;32(2):234. PMID: 11176320.

19. Tosun Z, Aksu R, Guler G, Esmaoglu A, Akin A, Aslan D, et al. Propofol-ketamine vs propofol-fentanyl for sedation during pediatric upper gastrointestinal endoscopy. Paediatr Anaesth. 2007 Oct;17(10):983-8. doi: 10.1111/j.14609592.2007.02206.x. PMID: 17767636.

20. Ament ME. Prospectivestudy of risks of complication in 6,424 procedures in pediatricgastroenterology. Pediatr Res1981;15:524.

21. Gilger MA, Spearman RS, Dietrich CL, Spearman G, Wilsey MJ $\mathrm{Jr}$, Zayat MN. Safety and effectiveness of ketamine as a sedative agent for pediatric GI endoscopy. Gastrointest Endosc. 2004 May;59(6):659-63. doi: 10.1016/s0016-5107(04)00180-4. PMID: 15114309.

22. Soyalp C, Yüzkat N. "Pediatrik hastalarda ameliyathane dışı anestezi uygulamalarımız: Retrospektif çalışma." Van Tıp Dergisi 26.2 (2019): 248-253

23. Koh JL, Black DD, Leatherman IK, Harrison RD, Schmitz ML. Experience with an anesthesiologist interventional model for endoscopy in a pediatric hospital. J Pediatr Gastroenterol Nutr. 2001;33(3):314-8.

24. Yang SM, Yi DY, Choi GJ, Lim IS, Chae SA, Yun SW, et al. Effects of Sedation Performed by an Anesthesiologist on Pediatric Endoscopy: a Single-Center Retrospective Study in Korea. J Korean Med Sci. 2020 Jun 1;35(21):e183.

25. Schmitz A, Weiss M, Kellenberger C, O'Gorman Tuura R, Klaghofer R, Scheer I, et al. Sedation for magnetic resonance imaging using propofol with or without ketamine at induction in pediatrics-A prospective randomized double-blinded study. Paediatr Anaesth. 2018 Mar;28(3):264-274.

26. Motamed F, Aminpour Y, Hashemian H, Soltani AE, Najafi M, Farahmand F. Midazolam-ketamine combination for moderate sedation in upper GI endoscopy. J Pediatr Gastroenterol Nutr. 